\title{
LAS CONSECUENCIAS ÉTICAS DEL PENSAMIENTO DÉBIL
}

\author{
Edickson Minaya \\ bttps://orcid.org/0000-0003-1095-6965 \\ Universidad Autónoma de Santo Domingo \\ bttps://doi.org/10.15304/ag.40.2.7203
}

\section{Resumen}

El presente trabajo, da cuenta de una Ética de la debilidad en el pensamiento hermenéutico del filósofo italiano Gianni Vattimo (1936). El artículo destaca que, en su propuesta, denominada "pensamiento débil", se dan las bases para una defensa, respeto y reconocimiento de las diferencias culturales en el contexto de la postmodernidad y que termina implicando a las minorías. Argumentos que observamos en distintos momentos de su producción textual, acentuando el paso de lo ontológico a lo ético. Intentamos responder a tres preguntas fundamentales: 1. ¿En qué consiste la ética debolista que se desprende de la hermenéutica nihilista de Vattimo? 2. ¿Cómo responde esta ética a la condición postmoderna, hoy en su fase multicultural; que construye diferencias, minorías y pluralidades? 3. ¿Cómo puede ser interpretadas las diferencias culturales desde el horizonte hermenéutico en que se inserta Gianni Vattimo?

Palabras clave: Ética de la debilidad, pensamiento débil, hermenéutica, pluralismo, posmodernidad, diferencias culturales.

\begin{abstract}
The present work gives an account of an Ethics of weakness in the hermeneutical thought of the Italian philosopher Gianni Vattimo (1936). The article highlights that, in his proposal, called "weak thinking", the bases are provided for a defense, respect and recognition of cultural differences in the context of postmodernity and that it ends up involving minorities. Arguments that I observe in different moments of his textual production, accentuating the
\end{abstract}

Recibido: 26/10/2020. Aceptado: 09/03/2021. 
passage from the ontological to the ethical. I try to answer three fundamental questions: 1. What is the Debolist Ethics that emerges from the Nihilist Hermeneutics of Vattimo? 2. How does this Ethics respond to the postmodern condition, today in its multicultural phase; that builds differences, minorities, and pluralities? 3. How can cultural differences be interpreted from the hermeneutical horizon in which Gianni Vattimo is inserted?

Keywords: Ethics of weakness, weak thinking, hermeneutics, pluralism, postmodernity, cultural differences.

\section{Introducción}

La sociedad actual se erige sobre la multiplicidad de valores, interpretaciones, visiones del mundo y culturas distintas. Estas características coinciden con el desarrollo de la tecnología, los medios de comunicación y el nuevo orden mundial que se fundamenta en una economía global. La vida que se funda, el Ethos que se constituye no está al margen de ese mundo. Razón de entender que la ética, como disciplina filosófica y saber práctico, no puede desestimarlo si quiere hacerse cargo de la moral. Argumentar sobre la eticidad, las formas de elección o acción posibles que involucra al fenómeno de la libertad humana.

Considerando este contexto, la filosofía de Vattimo formula respuestas a las interrogantes que el mundo de la tardomodernidad nos presenta (Gómez Arredondo, 2018). Dilucida las consecuencias que nos ha legado la metafísica tradicional de corte absolutista y dogmática que acaba encarnándose en una forma de poder con tendencia a eternizarse.

Para lograr el cometido de este trabajo, lo hemos dividido en tres partes. La primera, hace énfasis en la configuración de una ética de la debilidad como consecuencia del "pensamiento débil". La segunda, se refiere al papel que tiene la alteridad y pluralidad en la construcción del Ethos posmoderno en el ámbito de una sociedad tecnológica que afecta a todos los modos de vida. Pretende argüir cómo esta ética comprende la constitución del "hecho moral" y qué argumentos sostiene a favor del «otro diferente». La tercera, intenta aplicar estos mismos argumentos a la cuestión del derecho de las diferencias culturales que suele implicar también a las minorías.

\section{El horizonte ético-político del pensamiento débil}

En parte, la historia socio-cultural de Occidente ha sido la historia de la «fuerza». De la violencia arraigada. De la afloración de la barbarie. Y todas, en menor o mayor medida, han sido justificadas por discursos po- 
líticos, religiosos, metafísicos y hasta científicos. También, comprendidas a través de grandes relatos: la ideología del progreso, la del desarrollo. La tesis del "orden social" hegemónico y único. O, la fábula de la continuidad de los poderes, como garantía de la estabilidad espiritual y el desarrollo del mismo progreso.

Estos argumentos o relatos influyen en la vida moral de las personas, cuartando — debido a su reduccionismo - la libertad de los posibles modos de vida distintos y de las diferencias culturales. Frente a esta "violencia" psicológica, física y simbólica, surge el pensamiento débil. Corriente de la filosofía actual que emprende su vuelo a inicios de los años ochenta ${ }^{1}$.

Sin embargo, para entender las implicaciones éticas del discurso filosófico de Vattimo, es importante tomar en cuenta las etapas de su trayecto intelectual (Beuchot, 2009, pp. 79-86; Zabala, 2009, pp. 11-48; Castro, 2019, pp. 429-440; Zabala, 2019, pp. 9-13). Esto cumple con un doble objetivo: por un lado, dar con las motivaciones originarias de su pensamiento; y por otro, establecer los textos más significativos que recogen los argumentos (explícitos e implícitos) de dichas derivaciones éticas. Un elemento textual que puede ayudar a esclarecer la trayectoria del filósofo italiano son las distintas entrevistas a él realizadas, porque en muchas de ellas se ofrecen confesiones sobre su recorrido. Este ensayo escoge algunas, que serán reveladas a lo largo del artículo y presentadas en la bibliografía final.

Desde su tesis doctoral que trata sobre el concepto de producción en Aristóteles dirigida por su maestro Luigi Pareyson ${ }^{2}$, notamos tres momentos que se destacan. En ellos se desarrollan distintos temas que consolidan su visión filosófica. Aunque éstos no se distancian uno del otro, si algunos conceptos y problemas se van tornando dominantes en su discurso. En ese sentido, entendemos que se dan tres movimientos solapados al interno de su obra, estos son: el estético, el ontológico y el ético-político/religioso.

Esos giros son variaciones del desarrollo de la filosofía entendida por él como ontología de la actualidad, siendo esta idea la que unifica los momentos de su obra. Cada uno de esos trayectos abarca un conjunto de

\footnotetext{
${ }^{1}$ Sobre todo, con la famosa publicación de la antología compuesta por pensadores italianos, que lleva como título El pensamiento débil. Su publicación data del 1983. Generando, a partir de aquí, un debate que todavía permanece en la escena filosófica de hoy. Para una lectura en torno a las vicisitudes de dicha publicación puede verse el artículo de Castro, E. "Del pensamiento débil al nuevo realismo" en Bajo Palabra. II Época, 2019, pp. 429-440.

${ }^{2}$ Es importante aclarar, como lo ha conversado el mismo Vattimo (2007, p. 22), que en ese momento se sentía como un "premoderno" a propósito de su activismo católico, pese a incursionar en compromisos políticos.
} 
publicaciones que comprenden los problemas de su propuesta en general, denominada "pensamiento débil".

Debemos reconocer que las publicaciones de Vattimo tienen un carácter heterogéneo (Blanco Gálvez, 2007) atravesadas por el diálogo entre Nietzsche y Heidegger (Lisboa da Cunha, 2009, pp. 113-125; Torres Vizcaya, 2009, pp. 127-153). Por ejemplo, entre 1963 a 1974 publica textos relacionados con la estética, la ontología e interpretación de los autores mencionados, incluyendo a Schleiermacher. La publicación de Poesía y ontología cuya fecha original es 1968 (versión castellana de 1993), marca su interés por lo estético, aunque perfilando una interpretación ontológica sobre la obra de arte, influenciada por Pareyson, pero sobre todo por Heidegger. De hecho, Vattimo ha confesado que en aquellos años su estudio sobre este filósofo alemán se desarrolló paralelo a la acogida de las tesis fundamentales del pensamiento estético de su maestro en Turín. Luego, Vattimo confirmará que su interpretación en torno a Nietzsche y Heidegger evolucionó de forma independiente respecto a las ideas de Pareyson (Vattimo, 2007a, p. 25).

Con la publicación del Sujeto y la Máscara en 1974, nuestro filósofo se abre hacia el ideal de emancipación o liberación que veremos recurrente a partir de los años ochenta y más en el segundo milenio (Vattimo, 1996a, pp. 169-375; Desiato, 2009, pp. 277-292). En efecto, como tendremos la oportunidad de explicar, el pensamiento débil propone un ideal emancipatorio en términos nietzscheano-heideggeriano, pero en contraste con la violencia revolucionaria que pretende una toma de poder violenta. Cabe decir, que ya Vattimo se sentía no tanto como católico militante, sino como un hombre de izquierda que enriquecía sus lecturas con autores como Adorno, Lukács, Marcuse y Bloch.

Las aventuras de las diferencias de 1980 esbozan un diálogo con la escuela francesa (Foucault, Deleuze, Guattari y Derrida). Pese a algunas críticas realizadas a ésta, pensamos que le ayudará a analizar las fisuras provocadas en la tardomodernidad, elaborando un discurso que reclama todo aquello que queda afuera de la cultura hegemónica del capitalismo. Con la publicación de este conjunto se desarrolla las consecuencias políticas que el mismo autor ha confirmado (Vattimo, 2007a, p. 26) y que antes ya podemos apreciar en su ensayo "La devaluación de la política" del 1977 (Vattimo, 2007b, pp. 42-47).

El diálogo permanente con Nietzsche y Heidegger se traduce como el intento de aplicar estas filosofías a la suya, en dirección a comprender el mundo posmoderno configurado con ayuda de las nuevas tecnologías de la comunicación, la internet, el ciberespacio, los artefactos que permiten una 
interacción más "efectiva" y simultánea hasta el punto de impactar en la política u otras formas de poder (Vogt, 2010, pp. 229-230; Weiss, 2010).

No es hasta la publicación de Más allá del sujeto de 1981 y luego la antología El pensamiento débil de 1983 o, posteriormente, El fin de la modernidad de 1985, que la propuesta filosófica de Gianni Vattimo se consolidará como giro ontológico que pautará sus posturas ético-políticas y luego religiosas. Forjando una teoría de lo posmoderno en la cultura, de la mano del concepto de nihilismo ya asimilado en la interpretación de la obra de Nietzsche. Este conjunto de obras comprende un periodo importante. Al introducir la noción de "pensamiento débil" y "ontología del declinar", su filosofía despliega una concepción del ser como disociación, dilución, descomposición. El ser decae, muere y no puede entendérsele como algo perentorio (Vattimo, 1992, pp. 47-66, pp. 85-104; Vattimo, 1996b, pp. 2146, pp. 99-114, pp. 145-159).

En conexión con esto, en un artículo de opinión publicado en El País en 1987, titulado: "De la ideología a la ética", Vattimo habla de la importancia de su actualidad, término que acuña para referirse a esa "exigencia" creciente y difundida de la ética que hoy aún persiste. Reseña la necesidad de retomar estas cuestiones como rebasamiento de los planteamientos metafísicos que tienen pretensión de universalidad. A partir de este momento, la ética está llamada a desmontar aquellas ideologías que promueven desigualdad y buscan manipular la opinión pública en nombre de unos valores absolutos que tienen que ser aceptados sin más.

Según Vattimo, la llamada a la ética representa la alternativa de la crisis del fundamento. Los sistemas de valores son "representaciones y modos en que un individuo, un grupo o una clase pone en escena sus propios intereses, transfiriéndolos a un plano de presentabilidad, despojándolos de todo lo que tiene de demasiado feo inmediato y bárbaro" (Vattimo, 1987). En consecuencia, la ética ya no debe considerar los valores como "entidades" que representan el "verdadero fondo" de la realidad humana.

En atención a esto, Vattimo propone interpretar los medios de comunicación, su papel en el mundo posmoderno e impacto en la cultura. Dos obras de vital importancia analizan este acontecimiento: Ética de la interpretación (1991) y La sociedad transparente (1998a). En la primera, plantea la posibilidad de una ética de la interpretación en debate con la ética de la comunicación de Habermas (Vattimo, 1991, pp. 205-224; Blanco Gálvez, 2007; Santiesteban, 2013). La ética de la interpretación se pregunta si es posible, frente al relativismo y el "todo vale", sostener unos criterios y compromisos que el intérprete debe poner en evidencia, reconociendo sus 
prejuicios y expresando sus intereses de fondo. Aquí Vattimo pasa de la «vocación nihilista» de la hermenéutica, que ya había teorizado antes en El fin de la modernidad (Vattimo, 1996b, pp. 101-114), a su "vocación ética». Una vocación que ya estaba en ciernes en la obra Verdad y método de HansGeorg Gadamer y su rehabilitación de la filosofía práctica (1996, Vol. 1, pp. 383-395; Vol. 2, pp. 293-308, pp. 309-318).

La segunda, establece el diagnóstico de la correlación: medios de comunicación, tecnologías de la información y diversificación de las concepciones del mundo. Se recupera la idea heideggeriana en torno a la época de la imagen del mundo (Heidegger, 2010, pp. 63-90). La exorbitante multiplicación de ellas vuelve imposible una representación unitaria de la realidad y la historia.

Para Vattimo, la ética hermenéutica se sitúa en el horizonte de una "ética de bienes", más que de imperativos. Pero no asumiendo un "bien supremo" como en la tradición aristotélica, sino que la ética hermenéutica hace énfasis en los "valores compartidos por una comunidad histórica" (Vattimo, 1991, p. 207). Éstos no pueden ser reducidos a un principio superior que los haga practicables. Para emplear la terminología del filósofo, los valores son pensados como "logos-conciencia común» que no se sustraen ni a su historicidad ni al lenguaje empleado para discutir su validez de fondo. En contraste con la ética de la comunicación, que se guía por una concepción metafísico trascendental de los valores y postula un "punto de vista externo" normativo para considerar su validez.

Contra este "esencialismo", se desprende que "los bienes se configuran siempre en relaciones reciprocas, nunca de manera objetiva e impersonal" (Alegría Varona, 2017, p. 295). Vattimo al optar por un "reconocimiento radical de la intrínseca historicidad de la hermenéutica" (Vattimo, 1991, p. 210) arrastra esta posición hacia la ética y los "objetos" que caen bajo su comprensión. Pues, para él, los valores y la moral no se sustraen al devenir. Ignorar esta condición, significa que la ética corre el riego de abistoricidad en sus teorizaciones acerca de la moral, los valores y las normas.

Al hablar de la "vocación moral de la hermenéutica" o sus motivos éticos (Vattimo, 1991, p. 215), se apela a un concepto que más adelante retomaremos. Se trata de la noción de "pertenencia» que traduce la idea de que estamos articulados a una tradición cultural y lingüística, pero en la que no somos seres pasivos, ya que también respondemos a sus exigencias formulando nuevas interpretaciones y valores. En este punto, el autor propone un quiasma entre eticidad e historicidad.

En tanto el pensamiento débil adquiere la forma de hermenéutica —como teoría de la interpretación-, el único modo de corresponder con 
su «vocación ética» es permanecer inseparable a la denominada «instancia de la historicidad». Debe reconocerse como «evento del destino»: de las vicisitudes históricas de occidente junto al fenómeno de la secularización. El pensamiento débil, como hermenéutica, es el pensamiento del final de la metafísica y de la Europa secularizada. Aquí, secularización es también debilitamiento (Baleeiro, 2009).

A finales de la década del noventa, Vattimo sorprende al mundo académico con su giro religioso. Un reencuentro con su tradición de base: el cristianismo. Obras como Creer que se cree (1996c) y Después de la cristiandad (2002), serán claves en este periodo porque de ellos se extraen consecuencias éticas importantes que justifican la posibilidad y papel de la ética en el mundo posmoderno, a propósito del futuro de la religión. $\mathrm{O}$ si es posible hablar de un cristianismo no religioso, secularizado de fundamentos dogmáticos metafísicos.

En el primer texto, bajo la perspectiva nihilista y secularizada (Nontol, 2017) Vattimo redescubre el sentido originario de su vocación religiosa, la tradición cristiana católica. En el segundo, profundiza sobre su debilitamiento y propone otra interpretación del mensaje cristiano atendiendo a los conceptos de caritas y kénosis. Aunque ya había matizado sus aplicaciones en Creer que se cree (Vattimo, 1996c, pp. 61-63, pp. 72-77). Paradójicamente, este debilitamiento hace posible un nuevo retorno de las religiones en concordancia con la vocación ética del pensamiento débil. Pero ¿qué significa ese "retorno" a lo religioso y qué significado tiene para la ética de la debilidad?

Según Arenas-Dolz y Teresa Oñate (2009, pp. 73-76) al reintroducir el concepto de secularización se produce una renovada actualización del cristianismo como respuesta a la crisis de "las ideologías racionalistas ateas", que no quiere decir que la tendencia hacia la laicización se haya detenido. Todo lo contrario, esa emergencia de lo religioso es la expresión de un vacío provocado por ese proceso de laicización. Que se enfrenta a nuevas modalidades de fundamentalismos. Cuestión insistente en el pensamiento del último Vattimo que está guiado por un giro hacia lo político-emancipatorio. Con un nuevo acercamiento al comunismo y la crítica a la globalización. Este periodo está marcado por la idea de emancipación en conexión con la reprobación a su violencia implícita (Sützl, 2007; González Arribas, 2016).

Ahora vayamos a la pregunta que nos permitirá entender las consecuencias éticas de su filosofía: ¿qué es el pensamiento débil? Más que una corriente actual, es una actitud filosófica que enfrenta los dogmatismos, fundamentalismos y absolutos que gravitan y subyacen, parpadeantes, en 
nuestra cultura. Es también, como ha argumentado Teresa Oñate: una propuesta que busca "debilitar todas aquellas estructuras de la violencia, ya sean lingüísticas, religiosas, culturales, políticas, sexológicas o estéticas, que circulan por entre las costumbres y los hábitos, inconscientes o no, de las sociedades del capitalismo nihilista hipermoderno" (2006, p. 26). También puede ser descrito como un "estilo de filosofía" que, según sus diversos exponentes, pretende una reivindicación ética del pensamiento (Vattimo y Rovatti, 1990; Dal Lago y Rovatti, 1991).

Es una "antimetafísica". Va contra "el terror" a las "intenciones totalizadoras" y la reducción al "Uno" de los múltiples valores éticos, epistemológicos, estéticos, políticos... Así, niega "los rasgos metafísicos del pensamiento; y (...) la fuerza que éste siempre ha reivindicado para sí en virtud de su privilegiada capacidad de acceder al ser como fundamento" (Vattimo y Rovatti, 1990, p. 17).

En opinión de Sützl (2007), lo que permanece en vilo en este pensamiento es la cuestión del exceso o exabrupto que se desprenden de muchas ideologías que para justificarse apelan a un fundamento último como estadio de realización del sujeto.

En una entrevista publicada en 1989 en el diario español El País, Vattimo expresa que el pensamiento débil plantea "una ética de la tolerancia". Ética que invita a tolerar lo diferente, lo que se encuentra en condición de minoría. El filósofo de Turín plantea un concepto clave que acompaña a esta "ética de la tolerancia": la «reducción de las estructuras fuertes» como hilo conductor de la praxis del pensamiento débil. Y en Creer que se cree dice:

(...) tomar conciencia de la raíz de nuestras preferencias; de la relación explícita con su procedencia (origen) es de donde una ética del respeto y de la solidaridad recaba razonabilidad, precisión de contenidos, capacidad de hacerse valer en el diálogo con los otros (Vattimo, 1996, p. 47).

Considerando estos argumentos, si examinamos la génesis del pensamiento débil encontraremos que nace en relación con la crisis de las ideologías revolucionarias de los años setenta. Sobre todo, las impulsadas por una izquierda dogmática que terminó por reivindicar una "política del terror". Al respecto, Vattimo confirma que:

El pensamiento débil se desarrolló en estos años [años setenta] como un esfuerzo por imaginar una posibilidad de transformación social desde el interior del capitalismo tardo-moderno, de acuerdo con la idea de esos movimientos de liberación internos a la sociedad capitalista que no implican como condición de realización la toma de poder en el sentido clásico leninista. Hay una posibilidad de emancipación que aprovecha las oportunidades concretas de transformación (...) en vez de continuar mitificando una hipotética toma del poder. (1990b, p. 123, cursivas nuestras). 
Esta revelación, expone de inmediato el horizonte ético-político en que se inscribe el pensamiento débil. A propósito de su experiencia con el terrorismo italiano en los convulsivos años setenta. Sin embargo, su propuesta no pierde de vista la posibilidad de "cambiar el mundo", solo que no lo hace promoviendo una violenta toma de poder, pero sí desde la propuesta de una política transmetafísica (González Arribas, 2016, pp. 355-388).

Podemos contrastar la confesión antes citada con esta otra del 2007: "El aspecto de este pensamiento que ahora me gusta subrayar es el ético-politico, como delimitación del ideal revolucionario y rechazo de la violencia: se trataba de mantenerse fiel a una actitud revolucionaria contra la sociedad capitalista sin caer en el leninismo" (2007a, p. 30, cursivas nuestras).

Esta idea continua aún. En el 2016, en otra entrevista aparecida en La Contra (13/6/2016) se muestra reacio al neoliberalismo al cual llama "dogma" que pretende una "verdad universal" y "fuerte" con tendencias a concentrarse en un "pensamiento único" (Vattimo, 2016a, p. 4). Una vez más, la clave de la práctica ético-política del pensamiento débil es que "nos emancipamos de ellos debilitándolos" (Vattimo, 2016a, p. 2). Todo esto involucra una "política del debilitamiento» basada en la ética de la tolerancia, antes referida, que intenta "preservar la libertad, la diversidad y la autonomía del individuo" (Vattimo, 2016a, p. 3).

Por su parte, Pier Aldo Rovatti, uno de los cofundadores de este programa de pensamiento, ha dicho que en este opera una especie de «deconstrucción nihilista" que se traduce al "intento de quebrar el poder o, si se quiere, la «fuerza» de unidad" (Rovatti, 1990, p. 62). Estas formas de poder se expresan a través del «mito del Uno». Serie de atributos que evocan, desde cierta visión metafísico-dogmática, una supuesta seguridad en nuestras ideas de la realidad y de nosotros mismos. A partir de aquí, el programa del pensamiento débil puede sintetizarse en tres direcciones:

a) Elaborar una concepción del ser y de la verdad que lo defina en base a caracteres débiles.

b) Bajo estas consideraciones, se intenta definir al ser humano en términos de "mortalidad". Lo cual significa volver a pensarlo como ser frágil o desde la "fragilidad" de la vida. Como ser lábil o como figura incapaz de eternizarse. Con ello, el aspecto ético y antropológico no se pierde de vista. Ahora, el ser humano ya no es pensado con rasgos metafísicos; ni mucho menos como centro del mundo.

c) Esta línea de pensamiento es un esfuerzo por encontrar otra idea de emancipación (Vattimo, 1990a, p. 126; Sützl, 2007). Idea que se conecta, directamente, con una clara perspectiva ética y política (Santiesteban, 2013). 
El pensamiento débil apela a la «finitud temporal de la existencia». Cualidad propuesta como aquella condición primaria que funda la posibilidad de la historia como transmisión de mensajes. Idea que hereda de Heidegger y Gadamer cuando abordan el problema de la historicidad de la existencia y el papel de la tradición en la configuración de los modos de ser en el mundo. Desde aquí, Vattimo asume que la comprensión del «sentido de la existencia» está referida hacia el «devenir» de su propia historia. Hacia el depósito de significados que aportan las tradiciones, hacia los lenguajes de las experiencias, hacia las culturas.

Hemos indicado que el pensamiento débil propone el distanciamiento crítico respecto a la metafísica tradicional. Distensión que tiene como consecuencias tener que mirar "de forma nueva y más amistosa a todo el mundo de las apariencias, de los procesos discursivos y de las «formas simbólicas»" (Vattimo y Rovatti, 1990, p. 14). Esto implica ver lo humano en un horizonte de formas que caducan, no que perduran como una suerte de espíritu inmutable que subordina todo el derredor a su merced.

La experiencia del debilitamiento que así parece emanar de esta nueva actitud filosófica hace posible construir un discurso ético-político que haga comprensible el acontecimiento del ser, tal y como se da en las condiciones de nuestra cultura: globalizada, multicultural y postmoderna. Es por esta razón, que el pensamiento débil se deja atravesar por el pasado, el presente y el futuro (Vattimo y Rovatti, 1990, p. 17). Por el pasado: porque es capaz de dialogar con los mensajes de la tradición, que no es más que un diálogo con los otros. Por el presente: porque dirige su mirada hacia aquellos acontecimientos que nos atraviesan, y necesitan por ello, ser "objetos" de reflexión (ponemos el caso de la globalización, las guerras, el multiculturalismo). Por el futuro: porque se espera un "nuevo" encuentro con los valores anteriormente establecidos, y preparar así su posible metamorfosis hacia un ideal de emancipación no violento que pueda afianzar otra manera de entender la libertad y ensancharla (Leiro, 2018).

De ahí, que el "espíritu" del pensamiento débil resida en la ética. Pero la ética concebida como limitación de la fuerza (Dal Lago, 1990, pp. 161-168). La noción de debilidad apunta hacia un experimentar la piedad por lo ajeno, por lo otro; a practicar la caridad como establece el mensaje cristiano. El debilitamiento que procura este quehacer ético se convierte en "el hilo conductor emancipador en la historia del ser humano" (Vattimo, 2006, p. 37). Se trata, a fin de cuentas, de intervenir en el proceso de "adelgazamiento" de los autoritarismos o de una "disolución progresiva de todos los absolutos", con miras a fortalecer los espacios democráticos de las sociedades. 


\section{2. ¿Qué es la ética de la debilidad? Hacia una deconstrucción de la violencia y la fuerza}

$\mathrm{Al}$ renunciar a la lógica unívoca que funda la «razón-dominio», proyectada por la metafísica, nos queda por asumir una nueva actitud frente al mundo:

(...) la del que intenta guiarse por una ética de la debilidad, que resulta, sin lugar a duda, poco sencilla, bastante más ardua y menos reconfortante que las éticas al uso. La actitud de quien pretende alcanzar un difícil equilibrio entre la contemplación zozobrante propia de lo negativo y la cancelación de cualquier origen, la reconversión de todo en puras prácticas, en juegos, en técnicas válidas sólo dentro de ciertos límites (Vattimo y Rovatti, 1990, pp. 16-17).

La ética de la debilidad no es sólo un momento del pensamiento débil, sino su terreno más propio. Lo citado, pondera cuál es la estrategia de esta ética al considerar el "hecho moral": la acción, los valores, la forma de asumir un "bien", son pensados como prácticas sociales acompañadas de un discurso que ha de interpretarse. Obtienen, por lo tanto, su verdad dentro de cierto límite, referido a sus circunstancias.

En Más allá de la interpretación, Vattimo reafirma que "la ontología nihilista sucinta una legitima preocupación ética" (1995, p. 69). Aseverar el carácter interpretativo de la verdad produce un efecto de disolución de la racionalidad fuerte que procura las causas últimas para llegar a una descripción estricta de la realidad humana. Al realizar esta operación, los valores morales quedarían explicados de una vez por todas y ya no se debatiría sobre su carácter de alteridad o proponer opciones posibles. Los bienes quedarían fijados y no se reconocerían sus límites. Para Vattimo, con este pensamiento se culminaría a una especie de autoridad que hace callar las otras voces que no estarían de acuerdo con los bienes y valores fijados de antemano.

En continuidad con este argumento, si la ética de la debilidad recoge los mismos motivos del pensamiento débil, la manera de proceder para hablar de los valores morales, así como sus juicios, es apelando en primer lugar, a la experiencia de lo cotidiano. Que, según Vattimo (1990, p. 19), "se presenta siempre calificada desde el punto de vista histórico y preñada de contenido cultural". En consecuencia, no se supedita esencialmente a "principios últimos", sino a procedimientos. Pues, son los procedimientos que impregnan la moral como un fenómeno práctico que se vive al interior de una comunidad. Que no significa que toda acción o "hecho moral" quedan reducidos a un mero relativismo. Por el contrario, es en virtud de unos valores compartidos que se corrobora cada acción como si aquellos fueran 
el modelo por el que contrastar su validez. A sabiendas de que hay toda una dependencia histórica, o sea, una "procedencia».

Puesto que la ética debolista pretende dar respuesta a la configuración de los valores del presente que funda nuestro Ethos en el mundo posmoderno y tecnológico, las acciones morales son comprendidas como interpretaciones y propuestas que sirven a posibles formaciones de proyectos de vida. Por esa razón, esta ética se opone a las "pretensiones universalistas" de la metafísica. Es una ética de la vida humana. Profesión de "amor sacro" por lo frágil, que es lo humano. En efecto, Welsch (2009, pp. 127-133) ha resaltado que la filosofía de Vattimo es una filosofía para humanos, que se consagra a ponderar su condición histórica en el mundo de la tardomodernidad.

Esta ética nos invita a tomar conciencia sobre aquellos modelos de elección que terminan poniendo en peligro la vida humana a partir de valores metafísicos $^{3}$ (González Arribas, 2016, pp. 133-184). Y ya hemos señalado que, para el pensamiento débil, este tipo de metafísica se nos revela como cómplice de la violencia que enmascaran los discursos del totalitarismo y el Uno. Como son: los ultranacionalismos, el discurso de la guerra y de la limpieza étnica; los fundamentalismos religiosos y políticos; la homofobia, el racismo, la xenofobia, el terrorismo.

En este orden, un verdadero signo de madurez en la cultura occidental, según Vattimo, es su tendencia al debilitamiento. Una vez que nos damos cuenta del exceso que provoca la creencia en las estructuras fuertes de la metafísica del poder, hacemos lo posible por debilitarlos, por deconstruirlos e incluso, por cambiarlos. Sin embargo, esa tendencia a la secularización o debilitamiento no puede entenderse como un telos que debe por necesidad realizarse, sino como un llamado a optar por la deflación de los valores metafísicos en la vida moral, ya que hemos aprendido de su violencia al poner en peligro nuestros modos de vida.

El pensamiento débil realiza la crítica a esas "formas totalitarias" y reductoras de la vida humana. Desenmascarando "la creencia en una estructura estable del ser que rige el devenir y da sentido al conocimiento y normas a la conducta" (Vattimo, 1998b, p. 64). No sin razón, Vattimo argumenta que "Sólo podemos reconstruir una ética partiendo de la conciencia de que

${ }^{3}$ Es importante resaltar, por un interés metodológico, la manera en que Vattimo observa cómo el discurso metafísico genera cierta violencia cuando propone un sistema de verdades absolutas y valores cerrados. Con suma razón, Vattimo ha expresado (1998b, p. 74) que la base de la violencia metafísica consiste propiamente en el mecanismo de la remisión al Grund, a la fundamentación. 
no es posible una ética de principios que después se realizan como aplicación de un principio universal. Nuestra ética - dice-es una disolución de la universalidad" (1990b, p. 127, cursivas nuestras). El discurso ético de Vattimo enfrenta la práctica de querer tapar y borrar los derechos de las diferencias en nombre de "unas esencias universales y abstractas» que ejerce violencia hacia lo humano. Reivindicar estos derechos, ejerciendo la crítica a esa violencia, es tarea de la ética de la debilidad. Por eso, atiende a la experiencia histórica de la fuerza que ha circulado en Occidente, muchas veces motivada por la voluntad o deseo del poder desenfrenado.

En consecuencia, la ética de la debilidad pretende "llevar a término una especie de redención que haga justicia —es decir, que vuelva a dar la palabra- a todo aquello que ha sido excluido y olvidado en la historia lineal de los vencedores" (Vattimo, 1990a, p. 23). Como, por ejemplo, las minorías y las diferencias culturales. Que siempre son propensos al dominio, en tanto se les ha mirado como "objetos" que supuestamente obstaculizan la marcha de la razón política hegemónica. La ética de la debilidad también es una crítica a la historia.

Desde esta perspectiva, la ética debolista se sitúa en el contexto de "la crítica al proyecto ontológico que inscribe permanentemente el Ser en horizonte (idealista universalista) del racionalismo europeo moderno" (Ortega, 2004, p. 4). Y en este sentido, también ha de tomar en cuenta, para su argumentación, la crisis de los metarrelatos, denunciada por el discurso de la posmodernidad filosófica (Lyotard, 1996). La ética de la debilidad es consciente de que tal actitud surge de la crisis de los fundamentos (epistemológicos y morales). Que en el horizonte de la filosofía de Vattimo es también la quiebra de "una verdad universal y de un humanismo transcultural" (Vattimo, 2004, p. 9). Pero ¿cómo se debe construir una ética acorde con este acontecimiento?

Más que una actitud pesimista o derrotista, Vattimo ve la crisis de esos valores como chance. Como oportunidad de construir una concepción más débil de la condición humana, que perciba al ser humano como ser lábil y des-potenciado. Ya no como centro del mundo, sino como ser periférico. Ya no como sujeto transparente, sino como perteneciente a una tradición determinada. Junto a este posicionamiento práctico, el autor toma en cuenta la "tendencia" del ciudadano hacia la disipación de visiones del mundo que ya no pretenden un centro absoluto (Vattimo, 1998b; 2016b, p. 31) y todo esto tiene que ver con la crisis de la modernidad y de su sistema ideológico.

También esta crisis afecta a la ética. Que se resume en "el descrédito en el que ha caído el razonamiento "por principios», que se legitima al remitir 
a fundamentos de validez universal" (Vattimo, 2004, p. 58). Pero ¿a qué se debe este descrédito? Por una parte, a un cambio de rumbo en la mentalidad occidental provocada por las transformaciones políticas, económicas, sociales y culturales desde mediado del siglo XIX (Lyotard, 1996). Pero también, por la emergencia del pluralismo cultural a todo lo largo del siglo xx y este que corre (Vattimo, 2006, p. 32). Que no es más que una consecuencia de "la modificación de las relaciones políticas de Occidente y otros mundos culturales" (Vattimo, 2004, p. 58). El "choque cultural" ha hecho que Occidente cambie de perspectiva respecto a la forma de hacer válido sus "principios morales", incluso sus decisiones políticas y jurídicas.

Se vincula, igualmente, a la transformación en el plano filosófico: “(...) tiene que ver también con la crítica marxista, el descubrimiento del inconsciente por parte de Freud y la desmitificación radical a la que Nietzsche sometió la moral y la metafísica tradicionales, incluido el ideal mismo de verdad" (Vattimo, 2004, p. 58; cf. Nietzsche, 1982). En atención a todo esto, la ética de la debilidad se corresponde con nuestra época y con esos cambios, autoafirmándose con un acto responsable de interpretación:

Si la filosofía puede seguir hablando de ética racionalmente, esto es, de manera responsable ante las únicas referencias que se puede conceder - la época, la procedencia-, podrá hacerlo únicamente si asume como su explicito punto de partida - y no como fundamento- la condición de no-fundamentalidad en la que hoy se encuentra arrojada. (Vattimo, 2004, p. 60).

Esta propuesta ética no discute los problemas morales desde una perspectiva ahistórica. Empero, ha de comprometerse con la historicidad de los valores y la moral (Vattimo, 2004, p. 81). De tal modo que se hace acompañar de esas referencias históricas que tienen que ver con las vicisitudes de los valores morales en su proceso de construcción de acuerdo con su contexto cultural. En este sentido, Vattimo ha dicho que "sólo es posible hablar de ética si se mira cómo están las cosas, de hecho, en nuestra situación” (2004, p. 81), haciendo énfasis en los aspectos sociales de las normas morales.

Así, la ética de la debilidad toma en cuenta por qué hoy ciertos valores se cuestionan y qué produce un "nuevo clima ético". A raíz de esto, observa que en la actualidad se hace menos hincapié en el comportamiento personal o individual y en cambio se acentúa las consecuencias sociales de la acción (Vattimo, 2004, pp. 82-84; Blanco Gálvez, 2007, p. 63).

En ese sentido, se afirma que la "naturaleza" de la moral (costumbres, normas, modos de vivir) no tiene, no posee la misma "naturaleza" que los entes, como, por ejemplo, los "objetos" a que los científicos tienen acceso. Por lo tanto, el estudio de la moral ha de guiarse desde otra perspectiva. 
Y un concepto clave del argumento de Vattimo es "herencia», que se vincula con el de "procedencia».

La moral es herencia de la tradición. Algo así como aquellos contenidos vinculados a la vida; transmitidos desde la propia historicidad de la existencia bajo la forma de hábitos y normas. Precisamente, la moral no se reduce a una estela de principios. En oposición, la moral es una construcción social, de individuos que conviven entre sí que tienen el deseo de comunicarse $o$ de cooperar. Por eso, inventamos normas que hay que consensuar para equilibrar el juego de fuerzas. Pero ¿qué significa que este "hecho moral" es representable, solamente, con un acto de interpretación? Que aquello que obtengo, el conocimiento de la acción moral es una interpretación y no un conocimiento seguro, estable, que pueda ser minimizado a leyes. Desde este horizonte, queda en cuestionamiento la ética de los imperativos categóricos.

Sin embargo, el hecho de ganarse una interpretación no significa que sea un conocimiento desautorizado o sin capacidad para orientar o valorar actos, pues, en tanto este discurso ético corresponde a la época, significa que imprime "una especie de obligatoriedad que autoriza a hablar de racionalidad y eticidad" frente a nuestra situación actual (Vattimo, 2004, p. 59). La ética de la debilidad es, por tanto, una "ética sin metafísica" (González Arribas, 2016, pp. 319-354) o como prefiere llamarle el filósofo italiano una "ética posmetafísica":

a) Dado que este discurso ético no parte de primeros principios absolutos, sino desde su "disolución" en la cultura posmoderna, se "afirma", críticamente, "una pluralidad no unificable" (Vattimo, 2004, p. 60; Daros, 1998).

b) La ética de la debilidad es también una "ética de la finitud". Una ética construida en torno a la finitud de la existencia. Que debe entenderse desde mi condición como existente; desde mis límites en el mundo; frente a los demás, en tanto son miembros de una comunidad de intérpretes.

En definitiva, la ética que se desprende del pensamiento débil es un llamado a estimar la historicidad de la existencia como límite de nuestros valores. Es, también, vocación explicita a tener que presentar argumentos razonables a favor de la libertad y la democracia. Cae bajo su responsabilidad comprender las condiciones actuales de la vida moral, atendiendo a la alteridad como esa existencia que no puedo desaparecer en el nombre de la asunción de normas incondicionales, puesto que las diferencias culturales «están-ahí-con-nosotros». Nos invitan a que sopesemos nuestras elecciones políticas y jurídicas. 
Por eso, la distancia que se da entre culturas dispares ha de ser mediada por el diálogo. La ética tiene que desmentir aquella concepción que plantea que solo son posibles aquellos valores porque obedecen a una "cultura superior". Por el contrario, la ética de la debilidad está inclinada a situar las diferencias en el marco de la piedad y la solidaridad. Entiende que el Ethos es una "comunidad lingüístico-cultural concreta que se estatuye en el tejido de costumbres y cultura compartida" (Oñate, 2000, p. 12). Esta radicalidad hermenéutica debe entenderse como la tendencia a disolver cualquier pretensión violenta o de la ideología que representa una identidad utópica de valores puros.

\section{La ética de la debilidad como reconocimiento del otro}

Desde la ética de la debilidad, la noción del otro obliga reflexionar sobre el papel y función de la alteridad en la construcción del Ethos. Asimismo, alteridad dice: "otro distinto a mi yo" que, además, permanece irreductible a mi subjetividad o a mi poder. A mis intenciones. A mis deseos. Su intento de reducción sería dominio de su voluntad y violencia a su estatuto como persona. $\mathrm{O}$ en términos territoriales, invasión de su espacio de pertenencia. Y, por consiguiente, irrupción de su libertad.

Tomar en cuenta a los otros significa conceder el derecho a la participación, en todos los sentidos de la palabra: política, jurídica, cultural y hasta económica. Sin embargo, para que esto sea posible debe darse un cambio de actitud que responda al sentido de la cooperación. Es decir, siempre y cuando tengamos la voluntad de cooperar para que esta participación se dé en los ámbitos de la sociedad. Ya que el otro no está fuera de mí, sino «conmigo». Solo puedo comprenderlo cuando reconozco que vive junto a mí y participa de unos deberes y derechos.

El Ethos depende de una pertenencia cultural e histórica y se construye en un constante vínculo con los otros, en arduo proceso de interacción, comunicación y cooperación. Su "naturaleza", por tanto, es social y comunicacional. En efecto, el concepto griego de Ethos significa "morada" o "lugar habitual". Incluso "habitación", "residencia" y hasta "patria". En el contexto de la filosofía práctica, significa "hábito", "costumbre", "carácter", "manera de ser". En consecuencias, el Ethos no es una estructura inmutable, de la que podría "deducirse" los comportamientos o actitudes hacia la vida, un orden originario de las cosas. Es, repetimos, una construcción histórica, social, discursivo y cultural. Cuya validez se ventilan a través de las interpretaciones donde se llega a consensuar la verdad. 
De ahí, la necesidad de articular ética y hermenéutica, porque permite entender la configuración interpretativa de la vida moral (Blanco Gálvez, 2007, pp. 82-91). La moralidad es una recomposición infinita de la continuidad de la experiencia. Mientras que la ética hermenéutica (de la debilidad) la comprende bajo su historicidad. En ese sentido, Vattimo ha dicho:

\footnotetext{
El mundo se experimenta dentro de unos horizontes constituidos por una serie de ecos, de resonancias de lenguaje, mensajes provenientes del pasado, de otros individuos (los otros junto a nosotros, como las otras culturas). El a priori que hace posible nuestra experiencia del mundo es Ge-schick, destino-envio, o Ueberlieferung, transmisión. El verdadero ser no es, sino que se envía (se pone en camino y se manda), se trans-mite" (1990a, pp. 28-29).
}

Esta perspectiva sostiene que la escucha (o diálogo) y la interpretación (Conill, 2006, pp. 267) son los componentes fundamentales de la praxis debolista. Para ella, el Ethos es "con-vivencia". Y "con-vivir" significa "habitar". El "habitar" implica al otro, y, por tanto, establecer normas para la vida social. La ética de la debilidad se revela como una secularización de la metafísica e incluso del pensamiento cristiano. Secularización en Vattimo es también debilitamiento de los absolutos que terminan afectando a la filosofía práctica, en la medida en que ella se separa o libera de una concepción fuerte de esos valores morales que pretenden justificar normas desde aquellos absolutos. Esto permitirá que la ética de un paso decisivo hacia la interpretación de la historicidad de los valores. Ponderando el diálogo y la argumentación para su justificación.

La secularización implica libertad, liberación y diálogo cultural: "Si hay un principio por el cual la cultura europea de hoy en día pueda abogar en sus relaciones con otras culturas, esto es justamente el de ser una "cultura de antropología cultural», esto es, una cultura que reconoce la multiplicidad de las culturas" (Vattimo, 2007a, p. 36; cf. Sützl, 2007, pp. 227-247).

Este reconocimiento se reconduce hacia la contraposición de dos conceptos fundamentales del pensamiento occidental: veritas y caritas. El primero de ascendencia griega, impulsada por la filosofía y la ciencia. El segundo, de procedencia romana-cristiana, impulsado por la tradición humanista. La veritas está regida por la búsqueda de conocimiento. De establecer un orden del saber. La segunda, está regida por el amor. De instituir un Ethos que pueda vivirse y convertirlo en espacio compartible. La primera, está orientada por lo epistémico. La segunda, por la instancia de la ética. Que más que asegurar la verdad de los valores morales, se ha de referir a la caridad de ellos, defendiendo su equilibrio. 
La empresa Occidental estuvo siempre guiada por la búsqueda de la verdad. La verdad se impuso a la caridad. En este sentido, la ética de la debilidad es una reivindicación de la caridad y el amor que desde el horizonte del cristianismo se hacen relucir en la razón práctica, no ya desde una mirada puramente teológica, ni mucho menos desde una religiosidad dogmática, sino propiamente ética.

Lo que puede ganarse con esto, es fortalecer el ámbito político y práctico retomando el concepto de caridad como precepto que nos lleva a aceptar al otro. En este sentido, acontece lo que Teresa Oñate llama la "transformación intersubjetiva de la verdad" (2006, p. 20). Es decir, la verdad como construcción y consenso que conduce a la "integración compartida", y que tiene por base la racionalidad de la caridad y el amor en tanto relacionalidad.

La ética de la debilidad promueve, así, una racionalidad intersubjetiva que se apoya también en el modelo de la hermenéutica, ya que considera que el logos es «dia-logos». Y, por tanto, hay que ponerse de acuerdo si queremos fundar normas orientadoras de la vida. O sea, la racionalidad es, en virtud de una relacionalidad con los otros.

Antes que aceptar con cierta nostalgia la pérdida de trascendencia de los valores, debemos aceptarla como una vocación o tendencia hacia su transformación más humana y menos absoluta. Así, la ética que es capaz de renunciar al Otro como ser trascendente que todo lo gobierna, se convierte en una "ética de la negociación y el consenso", que, a su vez, no establece ningún "principio inmutable" (Vattimo, 2004, p. 88). Como podemos apreciar, estamos frente a una manera distinta de concebir la "razón práctica". Que no es aquella que dicta lo que debo hacer, sino la que me permite interpretar, comprender y valorar qué puede hacerse en cada situación. No es una postura que cae en el plano de lo individual o personal, sino en ámbitos públicos:

En el plano político, una tal reducción de la ética al consenso y al compartir no es algo de poca importancia: piénsese en hasta qué punto, todavía hoy, muchas legislaciones estatales se dirigen a la afirmación y defensa de derechos y deberes que se consideran «naturalmente fundados», pero que, con frecuencia, contrastan con la orientación afectiva de los ciudadanos. Es obvio que quizá nunca se podrá hacer coincidir los códigos con la afectiva voluntad general; pero, como ideal regulativo, éste parece ser el único que verdaderamente se puede adoptar en la condición de multiculturalismo en la que nos encontramos (Vattimo, 2004, p. 88).

No podemos asumir y dictaminar unas normas sin que se pase por el velo del diálogo. No hacerlo, resultaría arbitrario y sería una anomalía para el consenso de los intereses. La ética de la debilidad propone la solidaridad 
y piedad para con lo viviente. Entonces, quizás, el único “imperativo categórico" que esta ética conserva (y en efecto, puede conservarse) es la del respeto al otro. Sin embargo, como bien ha explicado Jesús Conill, esta filosofía "sólo puede presentarse como un discurso exhortativo, es decir, de carácter interpretativo y basado en argumentos retóricos, verosímiles" (2006, p. 267) y no como la descripción de una estructura inmutable.

"Discurso exhortativo". "Argumentos retóricos", por lo demás "verosímiles", parece la única manera en que esta ética puede expresar sus posiciones. Esto nos hace retornar a un breve ensayo de Vattimo titulado "Las apuestas políticas de la ingeniería genética" (2016c, pp. 329-331) en la que apela a una "ética argumentativa" en el sentido de que una vez conscientes de la pérdida de un fundamento último y evidente, no nos queda otra cosa que argumentar sobre nuestros valores morales. Es decir, ya no imponiendo una verdad, sino aludiendo a la caridad de los que participan en un "hecho moral", en tanto están impregnados del diálogo que viabiliza la convivencia social y la solidaridad. Y sólo se justifica cuando estos argumentos apelan a la no-violencia de las acciones hacia el prójimo. Precisamente, estamos en una época en que todavía somos amenazados por estallidos bélicos o de cualquier tipo de violencia. No obstante, la práctica de la caridad va más allá de un consentimiento religioso. Por el contrario, esta debe convertirse en la condición que puede fortalecer la convivencia social. De crear, cada vez, la apertura al ámbito del otro.

\section{A modo de conclusión}

¿Qué es lo débil, lo frágil que expone la ética de la debilidad? Lo débil es lo humano y el ser que se caracteriza en cada época, en cada envío de la tradición. ¿Cómo construir una ética acorde con este acontecimiento, es decir, de que lo humano es verdaderamente frágil y no algo duradero? Y más aún, ¿̇cómo responder a la condición posmoderna desde la ética? Esta ética tiene diversos nombres: ética de la debilidad, ética de la finitud, ética postmetafísica.

Hemos observado que a lo largo del pensamiento de Vattimo se da un paso importante de la ontología a la ética. Paso que recupera el motivo inicial del pensamiento débil, siendo este el horizonte político. Es decir, de una crítica radical a la realidad propuesta por la tradición metafísica, suficientemente debatida desde su hermenéutica, pasa a una consideración debolista de los valores éticos que no significa asumir un relativismo. 
Frente al poder hegemónico observa que los medios de comunicación y la tecnología de punta, hoy materializada también en las redes sociales y espacios virtuales, contribuyen a una dilatación de la sociedad y a emancipar a las minorías y diferencias culturales (Vattimo, 1998b, pp. 84). Esto conlleva a la pérdida de un centro y a una fragmentación vertiginosa.

Desde el punto de vista cultural, todas las minorías se sitúan en el horizonte de «lo diferente». Constituyen, además, una pluralidad que no se deja dominar por la cultura hegemónica. O al menos, desde una perspectiva en la que éstas quedan "eliminadas". Sencillamente, a las minorías y a las diferencias las tenemos "ahí", a "nuestros-ojos" y no podemos soslayarlas, pues conforman una verdadera problemática ética, política y jurídica.

Así, notamos que, en el pensamiento débil y la hermenéutica nihilista de Gianni Vattimo, en su vocación hacia la ética, se produce una especie de «dialéctica de la reciprocidad» que culmina en una ética de la debilidad en procura de la emancipación no violenta.

El reconocimiento de la historicidad de la existencia que hereda de Heidegger y su maestro Gadamer, lo lleva a incorporar la historia de los otros abriendo la posibilidad de un diálogo entre culturas; una apertura a las tradiciones, tanto locales como no locales. Con el fin de comprender, a su vez, el hecho de la pertenencia y el reconocimiento de derechos. Sin embargo, no se trata de un reconocimiento univoco sino de un reconocimiento mutuo que culmina en un reconocimiento de las alteridades que entran en el juego social.

Por otro lado, el pensamiento débil desprende otra consecuencia ética muy valiosa, consistente en aprender a escuchar las voces de los otros interlocutores, no importando las diferencias culturales. Estas diferencias pretenden ser reconocidas y escuchadas, pero, sobre todo, interpretadas desde su contexto (cf. Garzón, 1993; Camps, 1993). Y esta es la única razón por la que se exige transformar la mirada hacia sus valores y sus perspectivas morales con el objetivo de comprenderlas. Condición que se trata, más bien, de una actitud práctica. Y que puede ser definida como:

(...) atención devota hacia lo que, teniendo sólo valor limitado, merece ser atendido, precisamente en virtud de que tal valor, si bien limitado, es, con todo, el único que conocemos: piedad es el amor que se profesa a lo viviente y a sus huellas, aquellas que va dejando y aquellas otras que lleva consigo en cuanto recibidas del pasado (Vattimo, 1991, p. 26).

No es difícil aplicar este argumento a las minorías y diferencias culturales. La explicación citada exige un reconocimiento y un respeto que sólo puede ganarse en virtud de su atención devota, para, precisamente, 
comprender su papel en el marco de la cultura global. En este sentido, cabe decir, que las minorías y las diferencias son la viva expresión de la "disolución" de los grandes relatos como puntos de vistas únicos que legitiman una concepción reductora de la historia. Esto, porque en confrontación con los poderes hegemónicos les muestra que no son la única opción respecto a sus valores.

En vez de reducir las minorías y las diferencias culturales a una "simple presencia" que obstaculiza un proyecto nacional, la noción de pietas y caritas nos permite comprenderlas en términos de constitución existencial: como "proyecto-arrojado» y, por ende, como pertenecientes a un «mundohistórico concreto». La ética de la debilidad las comprende como ese mundo histórico preñado de valores y cargadas de experiencias significativas.

\section{Bibliografía}

Alegria Varona, C. "La moral y la ambivalencia de los bienes. Un análisis para la teoría de la justicia social" en Ideas y valores, N¹64, Vol. 66, 2017, pp. 293-319.

Arenas-Dolz, F. y Oñate, T. “Tras la interpretación” en Muñoz Gutiérrez, C., Leiro, D. M., Rivera, V.S. (Coords.). Ontología del declinar. Diálogos con la hermenéutica nibilista de Gianni Vattimo. Buenos Aires: Editorial Biblos, 2009, pp. 63-76.

Baleeiro, C. "O sentido de secularização em Vattimo" en Revista Eletrônica Correlatio N¹5 - Junho, 2009, pp. 80-91.

Beuchot, M. "Hermenéutica y sociedad en Gianni Vattimo" en Muñoz Gutiérrez, C., Leiro, D. M., Rivera, V.S. (Coords.). Ontología del declinar. Diálogos con la hermenéutica nibilista de Gianni Vattimo. Buenos Aires: Editorial Biblos, 2009, pp. 79-89.

Blanco Gálvez, J. F. "La "ética de la interpretación" de Gianni Vattimo" en A parte Rei, No54, noviembre, Monográfico Gianni Vattimo, 2007, pp. 1-142.

Camps, V. "El derecho a la diferencia" en Olivé, L. (Ed.). Ética y diversidad cultural. México: UNAM-FCE, 1993, pp. 85-100.

Castro, E. "Del pensamiento débil al nuevo realismo" en Bajo palabra. II Época, 2019, pp. 429-440.

Conill, J. Ética hermenéutica: crítica desde la facticidad. Madrid: Tecnos, 2006.

Dal Lago, A. "La ética de la debilidad. Simone Weil y el nihilismo" en Vattimo, G. y P. A. Rovatti, P. A. (Eds.). El pensamiento débil, Madrid: Cátedra, 1990, pp. 128-168. 
Dal Lago, A. y Rovatti, P. A. Elogio del pudor. Para un pensamiento débil. Barcelona: Paidós, 1991.

Daros, W. "El ser humano y la moral, en el clima light de la posmodernidad, según G. Vattimo" en Invenio: Revista de investigación académica, No2, 1998, págs. 37-55.

Desiato, M. "Vattimo y el problema de la liberación. Más allá del mundo y el hombre liberado" en Muñoz Gutiérrez, C., Leiro, D. M., Rivera, R. V. (Coords.). Ontología del declinar. Diálogos con la hermenéutica nibilista de Gianni Vattimo. Buenos Aires: Editorial Biblos, 2009, pp. 277-292.

Gadamer, G. Verdad y método. Vol. I y II. Salamanca: Sígueme, 1996.

Garzón, E. "El problema ético de las minorías étnicas" en Olivé, L. (Ed.). Ética y diversidad cultural. México: UNAM-FCE, 1993, pp. 31-57.

Gómez Arredondo, D. "Pensamiento débil y nihilismo: reflexiones en torno a la obra de Gianni Vattimo" en Revista Electrónica de Psicología Iztacala. 21, (4), 2018, pp. 29-40.

González Arribas, B. Reduciendo la violencia. La hermenéutica nibilista de Gianni Vattimo. Madrid: Dykinson, 2016.

Heidegger, M. Caminos de bosque. Madrid: Alianza Editorial, 2010.

Leiro, D. M. "El problema de la libertad y la fundamentación de la caridad en la hermenéutica de Gianni Vattimo" en Pensamiento al margen. Revista digital. $N^{o}$ especial Gianni Vattimo, http://www.pensamientoalmargen.com, 2018, pp. 192-229.

Lisboa da Cunha, M.H. "Nietzsche: la filosofía como ejercicio ontológico" en Muñoz Gutiérrez, C., Leiro, D. M., Rivera, V. S. (Coords.). Ontología del declinar. Diálogos con la hermenéutica nibilista de Gianni Vattimo. Buenos Aires: Editorial Biblos, 2009, pp. 113-125.

Lyotard, J. F. La condición posmoderna. Madrid: Cátedra, 1996.

Nietzsche, F. La genealogía de la moral. Madrid: Alianza Editorial, 1982.

Nontol, L. M. "Biografía, compromiso y cristianismo en Gianni Vattimo" en Boletín de Historia de la Tercera Orden Franciscana, N6, 2017, pp. 1-37.

Ortega, F. "Historia y éticas: apuntes para una hermenéutica de la alteridad" en Historia Crítica, Bogotá, No27, 2004, pp. 1-24.

Oñate, T. El retorno griego de lo divino en la postmodernidad: un diálogo con la hermenéutica nibilista de Gianni Vattimo. Madrid: Alderaban Ediciones, 2000.

Oñate, T. (et al). Ética de las verdades hoy: homenaje a Gianni Vattimo. Madrid: UNED, 2006.

Rovatti, P.A. "Transformaciones a lo largo de la experiencia” en G. Vattimo, P. A. Rovatti (Eds.). El pensamiento débil. Madrid: Cátedra, 1990, pp. 43-75. 
Santiesteban, L. C. "La ética hermenéutica de Gianni Vattimo. Hacia un Ethos de la no-violencia" en Revista Perseitas, No1 (1), 2013, pp. 14-27. Sützl, W. Emancipación o violencia. Pacifismo estético en Gianni Vattimo. Barcelona: Icaria, 2007.

Torres Vizcaya, "Nietzsche, Heidegger... Vattimo. La continuidad entre Nietzsche y Heidegger a la luz de Vattimo" en en Muñoz Gutiérrez, C., Leiro, D. M., Rivera, V. S. (Coords.). Ontología del declinar. Diálogos con la hermenéutica nibilista de Gianni Vattimo. Buenos Aires: Editorial Biblos, 2009, pp. 127-157.

Vattimo, G. "De la ideología a la ética" en El País, 7 de enero, 1987.

Vattimo, G. "El pensamiento débil es una forma de anarquía no sangrante". Entrevista en El País, 13 de junio, 1989, pp. 1-3.

Vattimo, G. "Dialéctica, diferencia y pensamiento débil" en G. Vattimo, P. A. Rovatti (Eds.). El pensamiento débil. Madrid: Cátedra, 1990a, pp. $18-42$.

Vattimo, G. "Gianni Vattimo, filósofo de la interpretación”. Entrevista realizada por José M.a Herrera y José Lasaga, en Revista de Occidente, $\mathrm{N}^{\circ} 104,1990$, pp. 115-132.

Vattimo, G. Ética de la interpretación. Barcelona: Paidós, 1991.

Vattimo, G. Más allá del sujeto. Nietzsche, Heidegger y la hermenéutica. Barcelona: Paidós, 1992.

Vattimo, G. Poesía y ontología. Valencia: Publicaciones de la Universidad de Valencia, 1993.

Vattimo, G. Más allá de la interpretación. Barcelona: Paidós, 1995.

Vattimo, G. Il soggetto e la maschera. Nietzsche e il problema della liberazione. Milano: Bompiani, $1996 a$.

Vattimo, G. El fin de la modernidad. Nihilismo y hermenéutica en la cultura posmoderna. Barcelona: Gedisa, 19966.

Vattimo, G. Creer que se creé. Barcelona: Paidós, 1996c.

Vattimo, G. La sociedad transparente. Barcelona: Paidós, 1998a.

Vattimo, G. "Metafísica, violencia, secularización". En: La secularización de la filosofía. Hermenéutica y posmodernidad. Barcelona: Gedisa. 1998b, pp. 63-88.

Vattimo, G. Después de la cristiandad. Hacia un cristianismo no religioso. Barcelona: Paidós, 2002.

Vattimo, G. Nihilismo y emancipación. Ética, politica y derecho. Barcelona: Paidós, 2004.

Vattimo, G. “¿Adiós a la verdad?”, en Oñate, T.; Royo, S.H. Ética de las verdades hoy. Homenaje a Gianni Vattimo. Madrid: UNED Ediciones. 2006, pp. 71-80. 
Vattimo, G. "Mi filosofía como ontología de la actualidad". Entrevista en Revista Anthropos. Huellas del conocimiento, 2007a, No217, pp. 19-41.

Vattimo, G. "La devaluación de la política" en Anthropos. Huellas del conocimiento, 2007b, No217, pp. 42-47.

Vattimo, G. "Gianni Vattimo, filósofo posmoderno; padre del pensamiento débil”. Entrevista con Lluís Amiguet en La Contra, 2016a, 13/6, pp. 1-5.

Vattimo, G. “¿Hacia un crepúsculo de los valores” en Bindé, J. (Dir.)? ¿Hacia dónde se dirigen los valores? Coloquios del siglo XXI, 2016b, pp. 29-35.

Vattimo, G. "Las apuestas políticas de la ingeniería genética" en Bindé, J. (Dir.). ¿Hacia dónde se dirigen los valores? Coloquios del siglo XXI, 2016c, pp. 329-331.

Vogt, E. "Postmodernity as the Ontological Sense of Technology" and Democratic Politics" en S. Benso, B. Schroeder (Eds.). Between Nihilism and Politics. The Hermeneutics of Gianni Vattimo. New York: Sunny Press, 2010, pp. 221-239.

Weiss, M. "What's Wrong with Biotechnology? Vattimo's Interpretation of Science, Technology, and the Media" en S. Benso, B. Schroeder (Eds.). Between Nihilism and Politics. The Hermeneutics of Gianni Vattimo. New York: Sunny Press, 2010, pp. 241-255.

Zabala, S. "La vida, la filosofía y los archivos de Gianni Vattimo" en $M i$ nerva. Revista del Círculo de Bellas Artes, 2019, pp. 9-13.

Zabala, S. "Gianni Vattimo y la filosofía débil" en Zabal, S. (Ed.). Debilitando la filosofía. Ensayos en honor a Gianni Vattimo. Barcelona: Anthropos, 2009, pp. 11-48. 